\title{
Investing in the future: a call for strategies to empower and expand representation of women in neurosurgery worldwide
}

\author{
*Samantha J. Sadler, BS, ${ }^{1}$ Ho Kei Yuki Ip, MBBS, ${ }^{2}$ Eliana Kim, BA, ${ }^{3}$ Claire Karekezi, MD, ${ }^{4}$ and \\ Faith C. Robertson, MD, MSc ${ }^{5}$ \\ ${ }^{1}$ Harvard Medical School, Boston, Massachusetts; ${ }^{2}$ Li Ka Shing Faculty of Medicine, The University of Hong Kong, Pokfulam, \\ Hong Kong; 3University of California, San Francisco School of Medicine, San Francisco, California; ${ }^{4}$ Department of \\ Neurosurgery, Rwanda Military Hospital, Kigali, Rwanda; and ${ }^{5}$ Department of Neurosurgery, Massachusetts General Hospital, \\ Boston, Massachusetts
}

\begin{abstract}
As progress is gradually being made toward increased representation and retention of women in neurosurgery, the neurosurgical community should elevate effective efforts that may be driving positive change. Here, the authors describe explicit efforts by the neurosurgery community to empower and expand representation of women in neurosurgery, among which they identified four themes: 1) formal mentorship channels; 2) scholarships and awards; 3) training and exposure opportunities; and 4) infrastructural approaches. Ultimately, a data-driven approach is needed to improve representation and empowerment of women in neurosurgery and to best direct the neurosurgical community's efforts across the globe. https://thejns.org/doi/abs/10.3171/2020.12.FOCUS20963
\end{abstract}

KEYWORDS women in neurosurgery; female representation; mentorship; scholarship; training

$\mathrm{T}$ HE neurosurgical community is beginning to recognize the need for greater female representation and that achieving gender parity in neurosurgery will require personal and institutional accountability. The proportion of women in neurosurgery demonstrates a positive growth trend, expanding from approximately $4.7 \%$ in 1980 to $15.5 \%$ in 2013 (American Association of Neurological Surgeons [AANS] data). ${ }^{1,2}$ The attrition rate of female neurosurgery residents declined from $25 \%$ in 1990-1999 to $17 \%$ in 2000-2009. ${ }^{1}$ Nonetheless, significant disparities in female representation continue to impede progress toward equity and parity. ${ }^{3,4}$ However, the encouraging increases in representation and retention may indicate that recent efforts are beginning to take effect.

Behind these positively trending numbers are numerous explicit efforts by the neurosurgery community to improve gender equity among practicing neurosurgeons, neurosurgery trainees, and aspiring neurosurgeons. These efforts vary in terms of strategies and goals, and their respective impacts on female representation in neurosurgery remain unclear. A better understanding of these strategies and programs may elucidate the most effective mechanisms for achieving gender parity and equity in neurosurgery, as well as encourage concerted, evidence-based approaches among key stakeholders.

Here, we describe explicit efforts by the neurosurgery community to empower and expand representation of women in neurosurgery.

\section{Methods}

We identified efforts centered around women in neurosurgery by reviewing broadly academic and institutional websites and the peer-reviewed literature, as well as by using web-based search engines and chain-referral sampling. ${ }^{5}$ We defined "exclusive opportunities for women in neurosurgery" as "explicit efforts by members and/or governing bodies of the surgery or neurosurgery community to empower and/or expand representation of women in neurosurgery." We also employed chain-referral sampling to maximize the likelihood of finding programs not identified through literature and internet searches. A qualitative

ABBREVIATIONS AANS = American Association of Neurological Surgeons; CNS = Congress of Neurological Surgeons; COSECSA = College of Surgeons of East, Central and Southern Africa; FIENS = Foundation for International Education in Neurological Surgery; LMIC = low- and middle-income country; WINS = Women in Neurosurgery; WiSA $=$ Women in Surgery Africa.

SUBMITTED November 1, 2020. ACCEPTED December 21, 2020.

INCLUDE WHEN CITING DOI: 10.3171/2020.12.FOCUS20963.

* S.J.S. and H.K.Y.I. contributed equally to this work and share first authorship. 
TABLE 1. Opportunities for women in neurosurgery

\begin{tabular}{|c|c|}
\hline Opportunity & Website \\
\hline \multicolumn{2}{|l|}{ Formal mentorship channels } \\
\hline WINS & http://www.neurosurgerywins.org/medical-students \\
\hline AANS & https://www.aans.org/Trainees/Residents-Fellows/Mentoring-Program \\
\hline AANS Young Neurosurgeons Committee & https://www.aans.org/Trainees/Young-Neurosurgeons-Committee \\
\hline CNS Resident Committee & https://www.cns.org/about/join-a-committee \\
\hline $\begin{array}{l}\text { Council of State Neurosurgical Societies Young Neurosurgeons } \\
\text { Section }\end{array}$ & https://csnsonline.org/committee/7.php \\
\hline Asian Women's Neurosurgical Association & http://www.hospitalbank.com/asiancns/ACNS_8.html\# \\
\hline WiSA & http://www.womeninsurgeryafrica.org/about-wisa/mentorship/ \\
\hline \multicolumn{2}{|l|}{ Scholarships \& awards } \\
\hline $\begin{array}{l}\text { WINS/Greg Wilkins-Barrick Chair Visiting International Surgeon } \\
\text { Award }\end{array}$ & http://www.neurosurgerywins.org/visiting-surgeon-fellowships \\
\hline Sherry Apple Resident Travel Scholarship & http://www.neurosurgerywins.org/the-sherry-apple-resident-travel-scholarship \\
\hline Louise Eisenhardt Resident Travel Scholarship & http://www.neurosurgerywins.org/louise-eisenhardt-resident-travel-scholarship \\
\hline WINS Leadership Development Award & http://www.neurosurgerywins.org/awards \\
\hline WiSA grants & http://www.womeninsurgeryafrica.org/scholarships-grants/ \\
\hline \multicolumn{2}{|l|}{ Training \& exposure opportunities } \\
\hline WINS lectureships & http://www.neurosurgerywins.org/ \\
\hline WINS Speakers Bureau & http://www.neurosurgerywins.org/speakers-bureau \\
\hline FIENS-Bassett Fellowship & http://www.fiens.org/fiens-basset-fellowship \\
\hline \multicolumn{2}{|l|}{ Infrastructural approaches } \\
\hline $\begin{array}{l}\text { European Association of Neurosurgical Societies Diversity in } \\
\text { Neurosurgery Task Force }\end{array}$ & https://www.eans.org/page/Diversity_Task_Force \\
\hline $\begin{array}{l}\text { World Federation of Neurosurgical Societies Women in } \\
\text { Neurosurgery Committee }\end{array}$ & https://sites.google.com/site/womeninneurosurgery/home \\
\hline Gender Equity Initiative in Global Surgery & https://genderequitysurgery.wordpress.com/ \\
\hline
\end{tabular}

thematic analysis was used to organize the interventions into broader categories.

\section{Results}

From our search, we identified 18 opportunities that satisfied our criteria defined above. To contextualize these opportunities, we constructed four themes: 1) formal mentorship channels; 2) scholarships and awards; 3) training and exposure opportunities; and 4) infrastructural approaches (Table 1). Formal mentorship channels are groups with membership exclusive to women currently practicing and/or interested in practicing neurosurgery, typically with the goals of facilitating mentorship for and fostering professional development of their junior members. Scholarships and awards are formal recognitions, with or without a conjunctive monetary prize, bestowed upon exclusively female applicants to further their neurosurgical career and/or celebrate their accomplishments. Training and exposure opportunities are programs delivered at various time points of an individual's surgical career with the goals of enhancing student interest and understanding prior to entering residency and optimizing training opportunities for neurosurgery applicants and residents. Finally, infrastructural approaches are concerted systems-level efforts to increase representation of female neurosurgeons in high-income countries and/or low- and middle-income countries (LMICs) by promoting diversity and inclusivity at an institutional level.

\section{Discussion}

Here, we discuss examples of programs, initiatives, and/or opportunities specifically geared toward increasing female representation and support in neurosurgery to contextualize each of the four themes.

\section{Formal Mentorship Channels}

Mentorship is widely recognized as a crucial component of surgical training for translating passion to tangible career progression. Many of the leading national and international professional neurosurgery societies have established platforms for mentorship and educational opportunities. For example, the AANS Young Neurosurgeons Committee created channels for practicing neurosurgeons to provide guidance to medical students and incoming residents. The Congress of Neurological Surgeons (CNS) Resident Committee and the Council of State Neurosurgical Societies Young Neurosurgeons Section actively involve residents in educational projects and leadership opportunities. However, the persistent gender gap in neurosurgery suggests that women may face additional barri- 
ers to accessing and benefitting from these opportunities, thereby inspiring initiatives around the world to specifically address this inequity. ${ }^{6}$

One approach is to establish programs and societies exclusively for women in (or interested in) neurosurgery. As a joint section of the AANS and CNS, Women in Neurosurgery (WINS) has been conducting programs and initiatives, such as career talks and mentoring programs, for the past 30 years to encourage and support aspiring female physicians to pursue neurosurgery. WINS was one of the first organizations to create specialized mentoring programs to pair undergraduate students, medical students, and residents with practicing female neurosurgeons, recognizing that early female representation and mentorship is essential to fostering success. Importantly, student membership in WINS is offered without a fee and is open to both medical students and premedical undergraduates.

Mentorship is an invaluable and irreplaceable component of surgical education, regardless of format and geographical location. Women in Surgery Africa (WiSA) is a group that provides support to female surgeons and medical students in 14 countries of the College of Surgeons of East, Central and Southern Africa (COSECSA). Since its establishment, the WiSA mentorship program has grown from 13 mentorship pairs in 2017 to 24 pairs in 2020 . Members are encouraged to access resources donated by the Royal College of Surgeons of Ireland and to organize mentoring sessions via Skype, email, and WhatsApp. Although this program is not exclusively targeted to neurosurgery enthusiasts, WiSA exemplifies the foundational importance of increasing representation of female surgeons in low-resource regions.

\section{Scholarships and Awards}

Multiple approaches are often intertwined to eliminate barriers to career advancement and to strategically include and reward outstanding women in neurosurgery, because a lack of both scholarly support and financial resources is a known factor that deters the pursuit of academic goals. ${ }^{7}$ For example, scientific meetings and conferences offer important, yet financially contingent, opportunities for education and networking in neurosurgery that may influence career opportunities.

WINS offers several travel scholarships and grants to outstanding residents with recognized contributions to the field to help defray the costs of travel and registration fees. These scholarships and grants include the WINS/ Greg Wilkins-Barrick Chair Visiting International Surgeon Award, Sherry Apple Resident Travel Scholarship, and Louise Eisenhardt Resident Travel Scholarship. These merit-based scholarships help facilitate more equitable career opportunities and encourage academic excellence. Nonfinancial awards are also used to achieve the latter. For example, another prominent award that recognizes young female neurosurgeons is the WINS Leadership Development Award, which is given to a WINS neurosurgeon who has practiced for less than 10 years and has demonstrated excellence in scholarship, research, clinical practice, mentorship, and leadership.

WiSA also offers a number of grants and awards to support exceptional female surgeons in the COSECSA re- gion. For example, the WiSA Travel Grant Award and the Shield Maiden Award have both been awarded to neurosurgeons to attend COSECSA conferences.

\section{Training and Exposure Opportunities}

Neurosurgery education is not limited to residency training. Rather, such education should be delivered at various time points during medical training, and the value of exposure to neurosurgery in medical school should not be underestimated. Zuccato and Kulkarni reported that early surgical exposure increased medical students' understanding of neurosurgery and encouraged passionate students to plan further neurosurgical clinical experiences. ${ }^{8}$ However, only a third of the participants in that study were women, highlighting how inequities in early opportunities may perpetuate future representational imbalance. WINS regularly holds named lectureships to honor pioneering female neurosurgeons and runs the Speakers Bureau, which provide neurosurgical exposure by offering lectures on neurosurgery careers to medical students.

As for residency programs, WINS emphasized the goal of $20 \%$ female representation in each class entering residency by 2012. Encouragingly, the proportion of women matched to neurosurgery residency positions increased from $10.7 \%$ in the 1990 s to $15.5 \%$ in $2013 .{ }^{1}$ This was a huge milestone given that currently only $6.1 \%$ of boardcertified neurosurgeons in the United States are women. ${ }^{9}$ That being said, we still have a long way to go before we reach equal gender representation in neurosurgery.

\section{Infrastructural Approaches}

Other organizations have prioritized structural changes to address systemic trends driving disparities. For example, the European Association of Neurosurgical Societies created the Diversity in Neurosurgery Task Force in 2019 to foster an inclusive environment for neurosurgeons of all genders and backgrounds by tackling barriers to career advancement. Furthermore, organizations have recognized the inherent links between global health and gender disparity, and these concepts have been explicitly integrated into their international disparity initiatives. The Gender Equity Initiative in Global Surgery was established in association with the Program in Global Surgery and Social Change to further address gender disparities and enhance inclusivity in surgery, obstetrics, and anesthesiology around the world through research, advocacy, and mentorship matching..$^{10}$ In addition, headed by renowned international female neurosurgeons, the Women in Neurosurgery Committee was established by the World Federation of Neurosurgical Societies to enhance female professional development and influence neurosurgical activities around the world.

\section{Limitations}

It is important to note that this article represents a proposal, and many of the aforementioned programs have not been validated for efficacy or effectiveness. Our list of programs and opportunities is not exhaustive, and new opportunities for greater awareness of gender equity in academia and clinical practice continue to emerge. More- 
over, although we chose not to include coed programs in our discussion, we recognize that such opportunities can still be leveraged by women. For example, the Foundation for International Education in Neurological Surgery (FIENS) awards the FIENS-Bassett Global Neurosurgery Fellowship, an international traveling fellowship, to neurosurgeons who are training in a residency program in an LMIC and those who have completed residency training in an LMIC within the past 5 years. The fellowship covers 3 months of expenses at a neurosurgical unit outside the fellow's country of residence. Although these programs serve an undeniably important role in expanding neurosurgical access globally, the proportion of women accepted into such coed programs as a whole remains low, much like the "coed" field of neurosurgery itself.

\section{Future Directions}

Given the variety of approaches and the unique nature of neurosurgery, a data-driven approach is needed to evaluate the effectiveness of each of these programs for advancing the careers of women in neurosurgery. Doing so will require defining and validating metrics of effectiveness and evaluation methodologies for these diverse approaches.

Additionally, attention should be paid to the influence of local context and culture on the relative success of a given approach. Tailoring innovations to local settings should be encouraged, yet proper evaluation of program outcomes is essential to informing resource allocation and achieving the most effective outcomes. It should be noted that many of these aforementioned programs are based in high-income, high-resource settings around the globe. Explicit, contextually informed efforts that increase female representation in low-resource settings through local empowerment are essential to ensuring that no country is excluded from this gender equity movement.

Finally, the neurosurgery field should ensure that female neurosurgical trainees and students of underrepresented ethnic backgrounds and other groups are included in these opportunities. Addressing intersectionality is indispensable to efforts that promote women in neurosurgery and avoid perpetuating other systemic biases and disparities.

\section{Conclusions}

This article reviews numerous strategies to empower and expand representation of women in neurosurgery globally. The four themes we provide help contextualize the approaches by leading institutions around the world that address gender disparities in neurosurgery, and we provide insights for where additional research and datadriven changes are needed. Although much progress needs to be made before women might be on par with men, we are hopeful that programs like these might continue to inspire progress.

\section{Acknowledgments}

We thank Hannah Weiss, MD, for her input and guidance on structuring this article.

\section{References}

1. Renfrow JJ, Rodriguez A, Liu A, et al. Positive trends in neurosurgery enrollment and attrition: analysis of the 20002009 female neurosurgery resident cohort. J Neurosurg. 2016;124(3):834-839.

2. Abosch A, Rutka JT. Women in neurosurgery: inequality redux. J Neurosurg. 2018;129(2):277-281.

3. Dixon A, Silva NA, Sotayo A, Mazzola CA. Female medical student retention in neurosurgery: a multifaceted approach. World Neurosurg. 2019;122:245-251.

4. WINS White Paper Committee; Benzil DL, Abosch A, Germano I, et al. The future of neurosurgery: a white paper on the recruitment and retention of women in neurosurgery. $J$ Neurosurg. 2008;109(3):378-386.

5. Natal B, Szyld D, Pasichow S, et al. Simulation fellowship programs: an international survey of program directors. Acad Med. 2017;92(8):1204-1211.

6. Bickel J. Advancing women in academic medicine. In: Shaywitz S, Hahm J-O, eds. Achieving XXcellence in Science: Role of Professional Societies in Advancing Women in Science: Proceedings of a Workshop. National Academies Press; 2004:38-42.

7. Cochran A, Neumayer LA, Elder WB. Barriers to careers identified by women in academic surgery: a grounded theory model. Am J Surg. 2019;218(4):780-785.

8. Zuccato JA, Kulkarni AV. The impact of early medical school surgical exposure on interest in neurosurgery. Can J Neurol Sci. 2016;43(3):410-416.

9. Renfrow JJ, Rodriguez A, Wilson TA, et al. Tracking career paths of women in neurosurgery. Neurosurgery. 2018;82(4): 576-582.

10. Kim EE, Velin L, Mazhiqi A, et al. Cultural barriers for women in surgery: how thick is the glass ceiling? An analysis from a low-/middle-income country. Letter. World J Surg. 2020;44(9):3186-3187.

\section{Disclosures}

The authors report no conflict of interest concerning the materials or methods used in this study or the findings specified in this paper.

\section{Author Contributions}

Conception and design: Robertson, Sadler, Ip. Acquisition of data: Sadler, Ip, Kim. Analysis and interpretation of data: Sadler, Ip. Drafting the article: Sadler, Ip, Kim. Critically revising the article: all authors. Reviewed submitted version of manuscript: Robertson, Sadler, Ip, Karekezi. Approved the final version of the manuscript on behalf of all authors: Robertson. Administrative/ technical/material support: all authors. Study supervision: Robertson.

\section{Supplemental Information \\ Videos}

Video Abstract. https://vimeo.com/510297374.

\section{Correspondence}

Faith C. Robertson: Massachusetts General Hospital, Boston, MA. frobertson@mgh.harvard.edu. 